\title{
Relationship between PASS cognitive processes and future thinking in children with autism spectrum disorder
}

\author{
Maryam Samadi ${ }^{1}$, Amir Ghamarani ${ }^{2 *}$ iD, Salar Faramarzi ${ }^{3}$
}

\begin{abstract}
1. PhD Student of Psychology and Education of Children with Special Needs, Faculty of Education and Psychology, University of Isfahan, Isfahan, Iran

2. Assistant Professor of Psychology and Education of Children with Special Needs, Faculty of Education and Psychology, University of Isfahan, Isfahan, Iran

3. Associate Professor of Psychology and Education of Children with Special Needs, Faculty of Education and Psychology, University of Isfahan, Isfahan, Iran
\end{abstract}

Recieved: 5 Apr. 2018

Revised: 23 Apr. 2019

Accepted: 8 May 2019

\section{Keywords}

PASS cognitive processes

Future thinking

Autism spectrum disorder

Corresponding author

Amir Ghamarani, Assistant Professor of Psychology and Education of Children with Special Needs, Faculty of Education and Psychology, University of Isfahan, Isfahan, Iran

Email: A.ghamarani@edu.ui.ac.ir

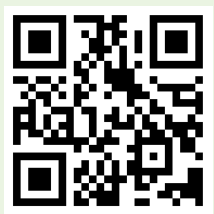

doi.org/10.30699/icss.21.4.74

\section{Abstract}

Introduction: PASS cognitive processes dysfunction is considered as a common feature of autism spectrum disorders. It seems likely that any breakdown in this capacity might impact on the capacity for future thinking in this group. Accordingly, this study aimed to investigate the relationship between PASS cognitive processes and future thinking in children with autism spectrum disorder in the city of Isfahan.

Methods: The research design was descriptive and correlational. The study population included all children 6-8 years old with a high-functioning autism spectrum disorder in Isfahan. The sample included 15 students with high-functioning autism who were selected by convenience sampling method. The Cognitive Assessment System, Autism Spectrum Screening Questionnaire, and Trip Task were used to collect data.

Results: The statistical results showed that the correlation coefficients between future thinking and PASS cognitive processes (planning, attention, simultaneous and successive) were significant at the $(\mathrm{P} \leq 0.05)$.

Conclusion: These findings provided evidence regarding cognitive mechanisms that may be related to the defects of future thinking in autism spectrum disorder. Besides, obtained results could have crucial implications in the clinical and theoretical level

Citation: Samadi M, Ghamarani A, Faramarzi S. Relationship between PASS cognitive processes and future thinking in children with autism spectrum disorder. Advances in Cognitive Sciences. 2020;21(4):74-83. 


\title{
رابطه بين فر آيندهاى شناختى ياس و تفكر آيندهنكر در كودكان با اختلال طيف اوتيسم
}

\author{
مريم صمدى'، امير قمرانى "iD ، سالار فرامرزى"

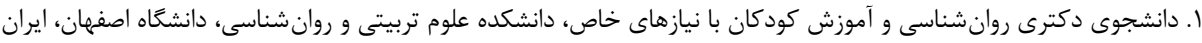

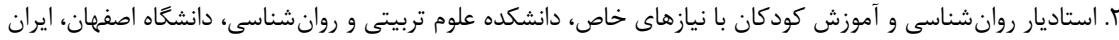

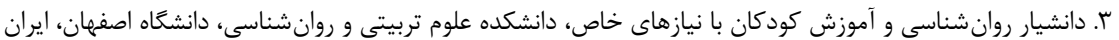

مقدمه: نقايص فرآيندهاى شناختى پاس (PASS) ويثگى معمول افراد با اختلال طيف اوتيسم است و به نظر مىرسد هر نقصى در اين توانايى ممكن است بر توانايىهاى ديكر از جمله تفكر آيندهنكر در اين گروه تأثير بخذارد. بر اين اساس، يُوهش حاضر با هدف بررسى رابطه فرآيندهاى شناختى PASS و تفكر آيندهنكر در كودكان با اختلال طيف اوتيسم در شهر اصفهان انجام كرفت. روش كار: طح اين يزوهش توصيفى از نوع همبستكى بود. جامعه بروهش شامل كليه كودكان ^-4 سال مبتلا به اختلال طيف اوتيسم با عملكرد بالا در شهر اصفهان بود. نمونه مورد بررسى در اين يزوهش، ها دانشآموز مبتلا به اختلال طيف اوتيسم با عملكرد بالا بودند كه به صورت در دسترس انتخاب شدند. براى گردآورى دادها از سيستم ارزيابى شناختى ويرايش دوم، يرسشنامه سنجش دامنه اوتيسم و تكليف سفر استفاده كرديد. يافته ها: نتايج تحليل آمارى نشان داد كه ضرايب همبستكى محاسبه شده بين فرآيندهاى شناختى PASS با تفكر

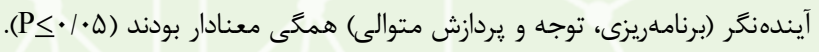
نتيجهَّيرى: يافتههاى اين يروهش شواهدى را در مورد مكانيسمهاى شناختى ارائه مى دهد كه ممكن است با نقايص تفكر آيندهنكر در اختلال طيف اوتيسم رابطه داشته باشد. اين نتايج مىتواند بيامدهاى مهمى را در سطح نظرى و بالينى ارائه دهد.
دريافت:

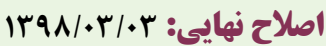
ئنيرش: وازههاى كليلىى فرا يندهاى شناختى پِاس

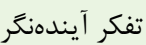
اختلال طيف اوتيسم

نويسنله مسئول

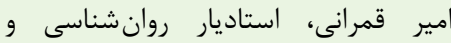
آموزش كودكان با نيازهاى خاص، دانشكده

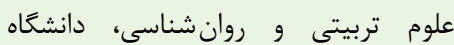
اصفهان، ايران

ايميل:A.ghamarani@edu.ui.ac.ir

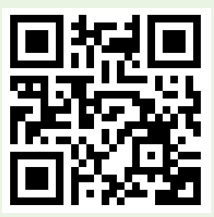

do

doi.org/10.30699/icss.21.4.74

مقلدمه

ميزان شيوع اختلال طيف اوتيسم افزايش يافته به گونهاى كه در هر كودك، ا كودى در سن مدرسه را تحت تأثير قرار داده است (r). با اين توصيف امروزه اختلال طيف اوتيسم برخلاف گذشته ديخر يك وضعيت

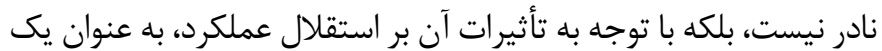
نخرانى اجتماعى بزرگ مطرح مى شود (1). در سببشناسى اختلال طيف
اختلال طيف اوتيسم (Autism Spectrum Disorder)، اختلال عصبى_رشدى است كه بر اساس دو محور رفتارى؛ تأخير يا نقص در ارتباط و تعامل اجتماعى، رفتارهاى تكرارى و علايق محدود تشخيص داده مىشود (1)، اين اختلال قبل از سه سالخى شروع و نقايص و ناهنجارىهاى آن در سراسر عمر ادامه مى يابد. طى جند دهـ كذشته 
كودكان اوتيسم عملكرد بدترى در تكاليف مربوط به تصور خويشتن در آينده نسبت به تكاليف مكانيكى داشتند اما كودكان عادى در هر دو نوع تكليف عملكرد مشابهى داشتند. اين نتايج در يزوهش Marini و همكاران نيز تكرار شده است (1)). از سوى ديكر، شواهد حاصل از داز مسيرهاى يزوهشى مختلف در روانشناسى و علوم اعصابشناختى بر

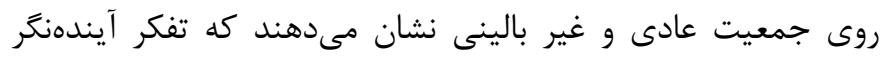

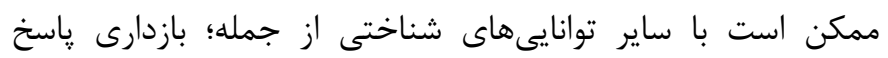

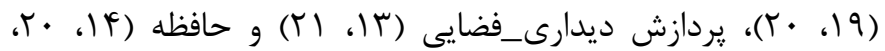
T'Argembeau و و ارتباط داشته باشد. براى مثال، در مطالعه همكارانش رابطه بين عملكردهاى اجرايى و تفكر آيندهنكر مورد بررسى

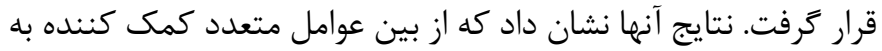

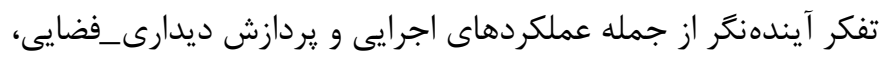

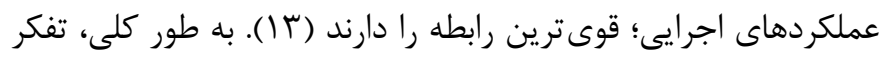

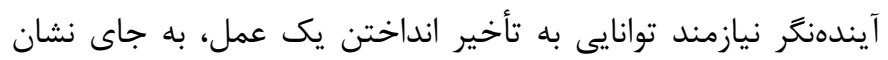

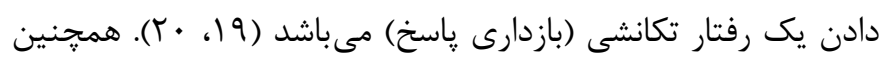
يیشبينى جزئيات حسى توليد شده حين تصور رويدادهاى آينده

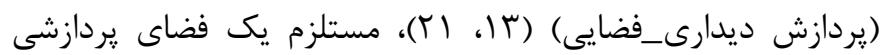

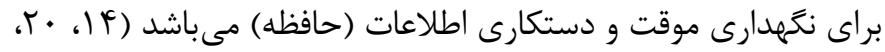

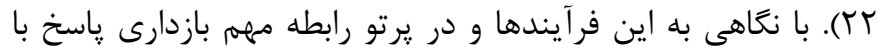

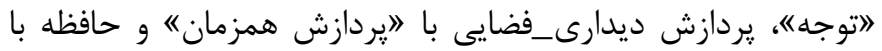
"يردازش متوالى" مىتوان شاهد رابطه مهم فرآيندهاى نظريه ياس Attention-Arousal, Simultaneous and Successive (PASS)) با تفكر آيندهنغر بود. The Planning, نظريه PASS، يك نظريه يردازش شناختى (برنامهريزى، توجه،

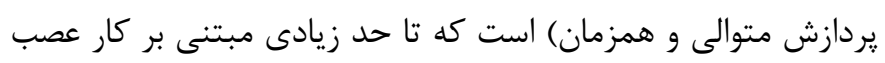

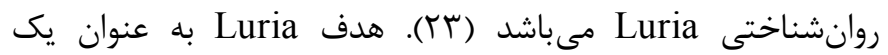
عصبشناس طراحى نظامهاى مغز و واكنشهاى مسئول در فرآيندهاى رفتارى پيجيجيده، به خصوص فرايندهاى سطوح بالاى مرتبط با ٍذيرش

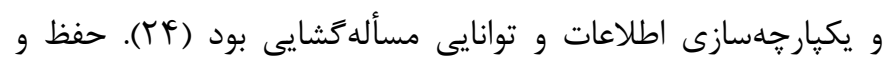

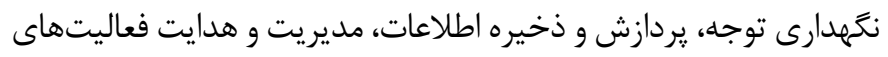
ذهنى مستلزم فعاليت واحدهاى عملياتى است كه جهت ايجاد يك

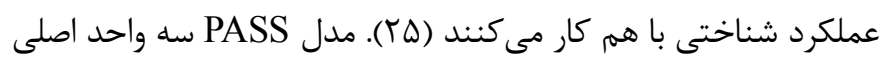

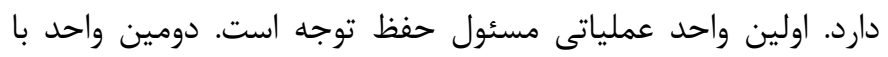
استفاده از فرآيندهاى همزمان و متوالى، اطلاعات را دريافت، رمزكذارى، يردازش و ذخيره مى كند و سومين واحد، فعاليت ذهنى را برنامهريزى، تنظيم و هدايت مى كند (rآ). اولين واحد در ساقه مغز، دومين واحد در لوبهاى يسسرى، آهيانهاى و گيجكاهى و واحد سوم در لوب يِيشانى
اوتيسم، اخيرا اين اختلال به عنوان يك ناهنجارى عصبشناختى در نظر كرفته شده و علاوه بر علايم تشخيصى، ساختارهاى مغزى غيرطبيعى و

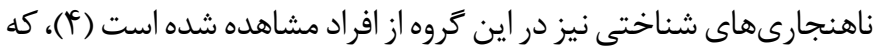
اين موضوع به نوبه خود اهميت نقايص شناختى و ارزيابى آن در كودكان آنسان

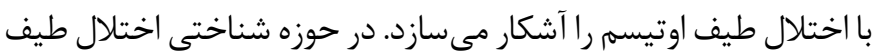

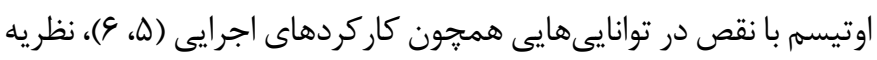
ذهن (Theory of mind) (V) ( ) و تفكر آيندهنكر (Future thinking) مشخص مىشود (9-9 (1). در اين ميان سازه اخير، يعنى تفكر آيندهنكر به عنوان مكانيسم احتمالى ديخرى كه به تبيين نشانههاى اختلال طيف

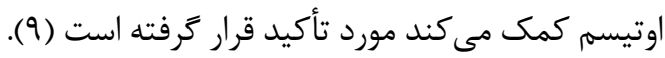
تفكر آيندهنكر همان توانايى تصويرسازى ذهنى منى از حوادث احتمالى آينده و يا توانايى فرد در تصويرسازى خلاقانه از احتمالات

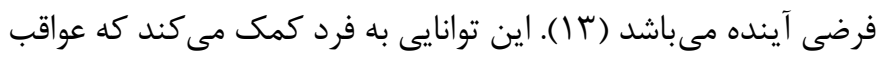

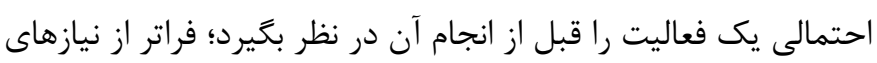

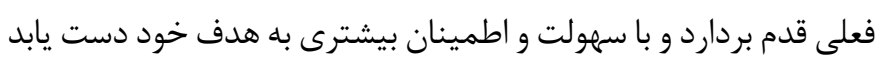

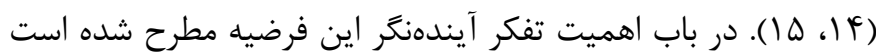
كه تفكر آيندهنكر مىتواند به عنوان تبيينى براى نقايص كودكان اختلال

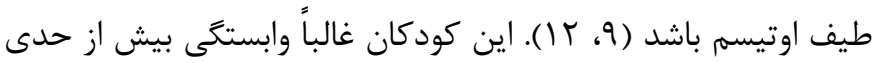
به رفتارهاى تكرارى و كليشهاى نشان مىدهند و فاقد انعطافيذيرى رفتارى مشاهده شده در رشد معمولى هستند (1). ممكن است اين

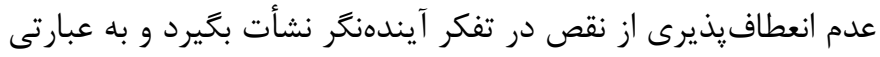

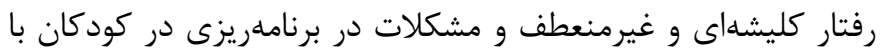

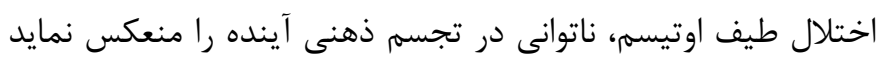

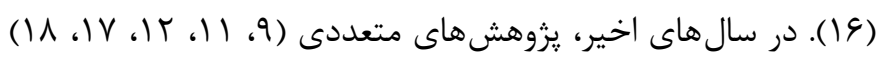
به بررسى تجربى تفكر آيندهنكر در اختلال طيف اوتيسه يرداختهاند و به عملكرد مختل در اين كروه بالينى يى بردهاند. در يك مطالعه، Lind و Bowler از شركت كنندكان خواستند رويدادهاى شخصى دورههاى زمانى مختلف رادر كذشته و آينده توصيف كنند. آنها دريافتند كه افراد با رشد عادى عملكرد بهترى در تفكر آيندهنكر نسبت به افراد اوتيسم

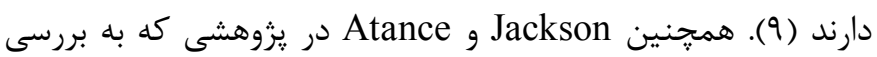

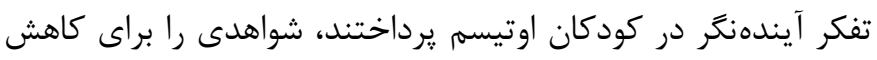

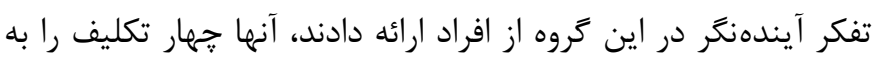

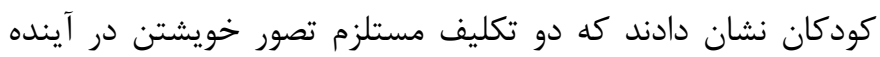

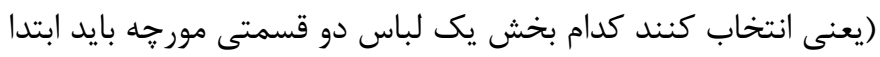
يوشيده شود يعنى بدن يا سر) و دو تكليف شامل بيشبينى در مورد يريامدهاى تكاليف مكانيكى بود (مثلا آيا يك قاشق شكافدار در انتقال دانهاى نشاسته موفقتر است يا يك جعبه كوجى بدون در) (IV). 
رضايت آنها كسب گرديد. ملاك ورود كودكان اوتيسم به يزوهش شامل برخوردارى از ملاكهاى اختلال طيف اوتيسم بر اساس ينجمين راهنماى

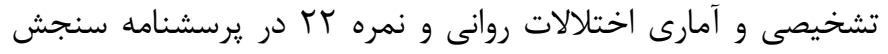

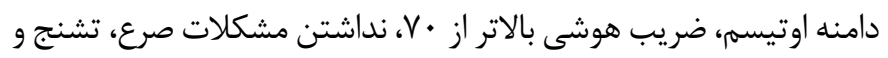

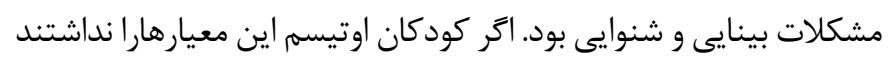

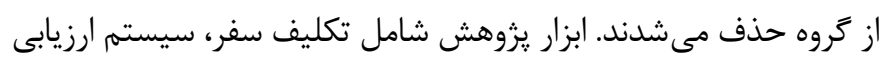

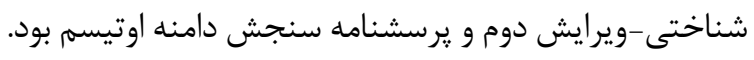
تكليف سفر: تكليف سفر توسط Atance و Meltzoff براى سنجش دون تفكر آيندهنكر طراحى شده است (9؟). در يزوهش حاضر يس إز ترجمه مقياس توسط يروهشكران و ترجمه معكوس توسط دو نفر از دانشجويان دكترى زبان انكليسى، ترجمه فارسى با اخذ نظر از اساتيد روانشناسى تهيه شد. اين ابزار شامل يك كتابجه حاوى كان آتصوير اصلى بزرك به به

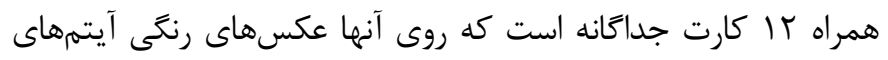

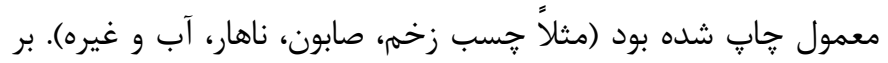

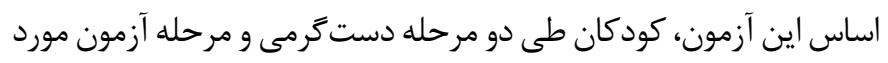

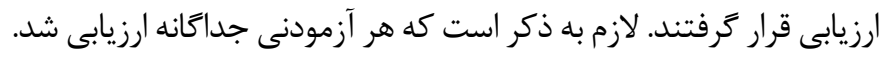

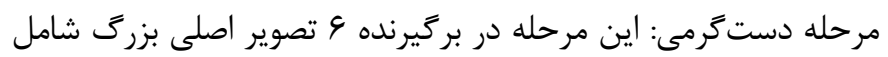

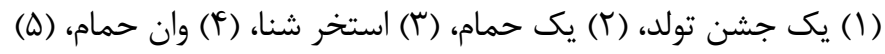

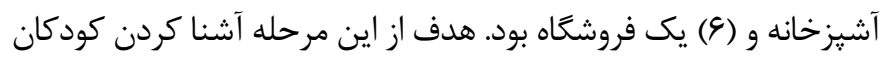

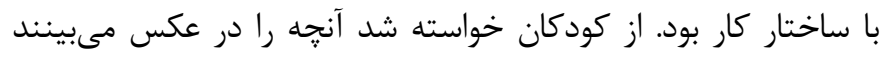

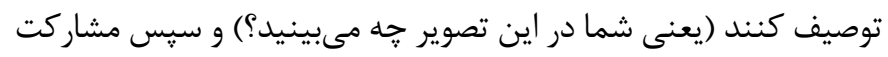

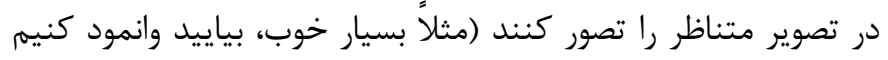

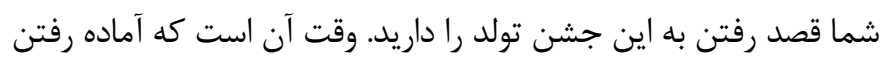

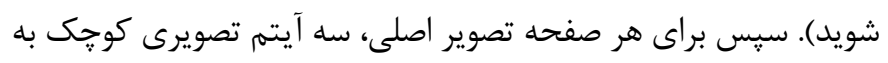

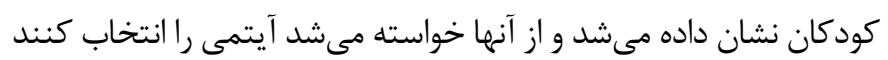

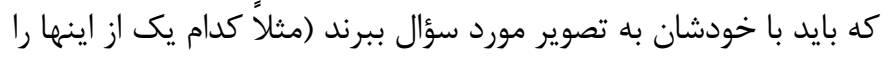
بايد با خود بياوريد؟). براى هر تصوير اصلى بزرك يك آيتم درست (مثلاً

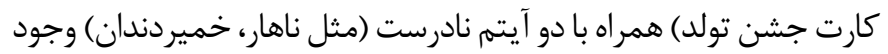

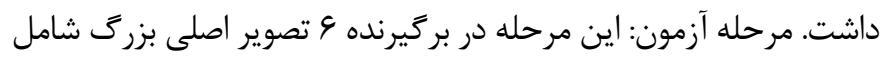

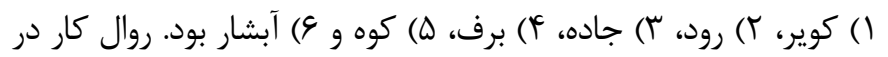

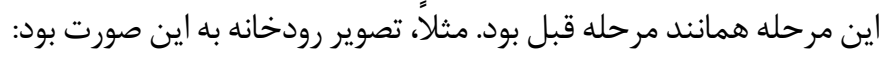

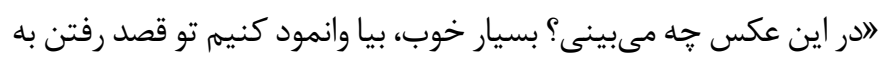

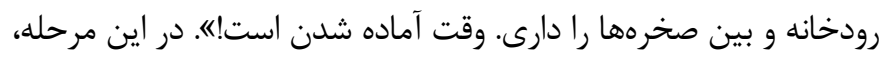

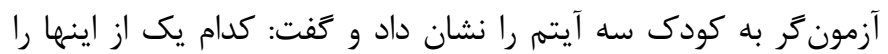
بايد با خود بياورى: يك بالشت، جسب زخم يا خمير دندان؟. نمره كذارى: دلايل كودكان براى انتخابهاى آيتم نمرهذارى شد. براى هر تصوير نمره

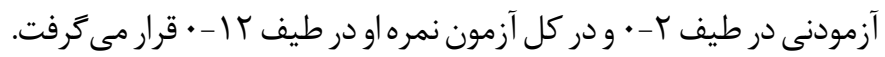

عمل مى كند (צ)). جهار فرآيند موجود در نظريه PASS، ساختارهاى نوروسايكولوزيكى مانند كاركردهاى اجرايى (برنامهريزى)، بازدارى ياسخ (توجه)، تكاليف ديدارى_فضايى (فرايند همزمان) و حافظه (فرآيند

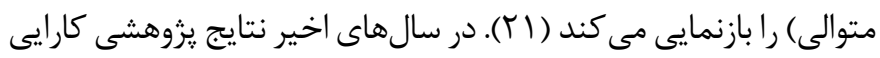

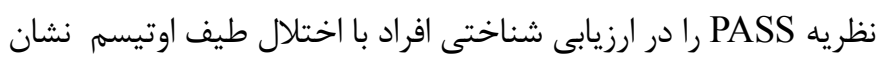

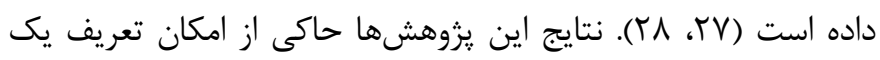

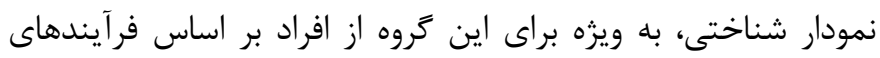
PASS با رشد معمولى در فرآيندهاى شناختى PASS نمرات يايينترى دارند. با توجه به نقايص افراد با اختلال طيف اوتيسم در فرآيندهاى شناختى PASS

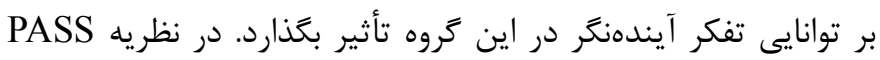

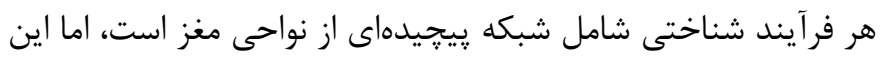

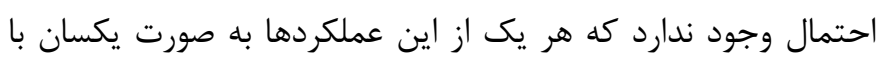

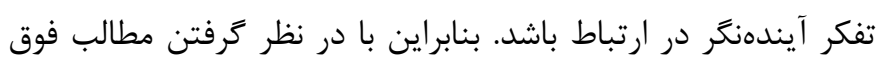

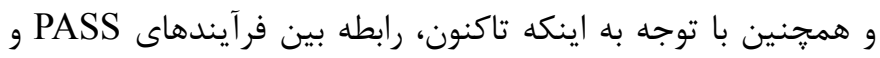

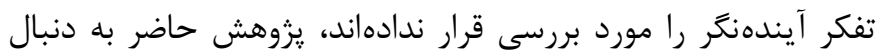
بررسى رابطه بين فرآيندهاى شناختى PASS و تفكر آيندهنكر بود. در اين راستا، هدف اصلى يزوهش حاضر اين بود كه رابطه بين فرآيندهاى

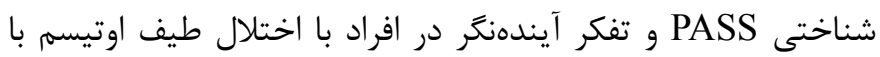

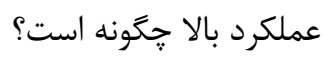

\section{روش كار}

يزوهش حاضر توصيفى از نوع همبستگى بود. جامعه يزوهش را كودكان

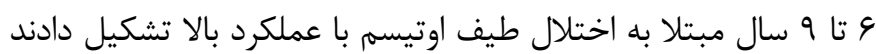
كه در طول مدت انجام يزوهش در يكى از مركز آموزشى_درمانى شهر

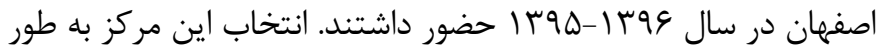

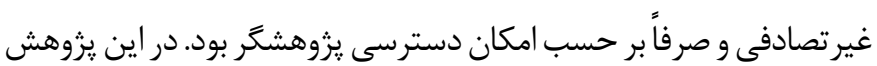

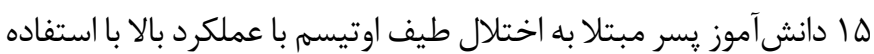

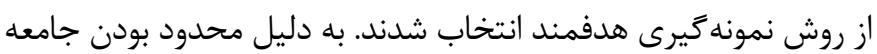

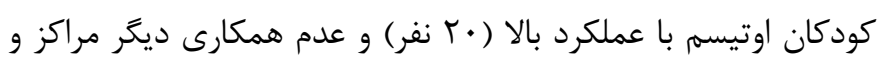

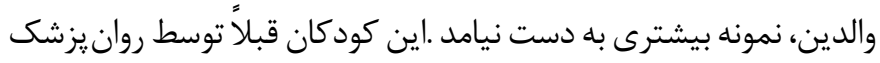

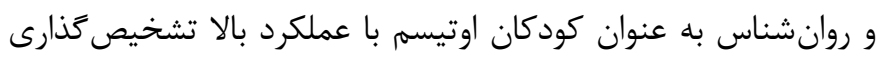
شده بودند، براى تكميل تشخيص يزوهشكر نيز از برسشنامه سنجش دامنه بانه اوتيسم)(Autism Spectrum Screening Questionnaire(ASSQ) استفاده كرد. به منظور رعايت موازين اخلاق در يزوهش، پيش از اجراى ثروهش با مسئولين و والدين كودكان هماهنگى صورت گرفت و 
مىدهد كه فرآيندهاى شناختى با سن افزايش مىيابد و رشد آن از يك روند سنى تبعيت مى كند. اين نتايج نشاندهنده رابطه بين عملكرد در مقياسهاى توانايىهاى شناختى و سن بوده است و جنبه مهمى از روايى مىباشد (آ). در اين مطالعه ضرايب اعتبار (آلفاى كرونباخ)

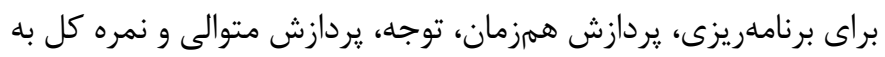

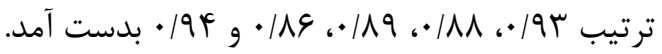
يرسشنامه سنجش دامنه اوتيسم (ASSQ): ابزارى است كه توسط Ehlers و همكاران طراحى شده است (זr)). اين يرسشنامه • مV FV ماده دارد و توسط والدين يا معلم تكميل مىشود. هر ماده نمره

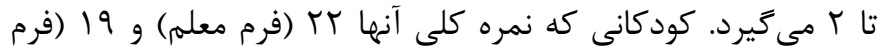
والدين) باشد به عنوان مبتلا به اختلال اوتيسم با عملكرد بالا شناخته

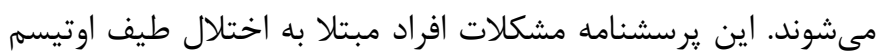

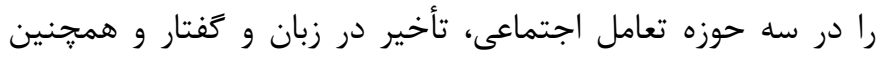

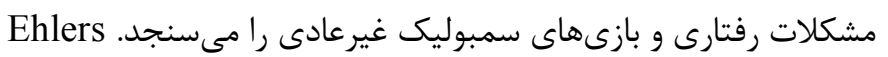

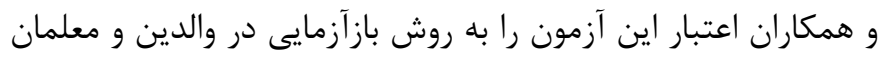

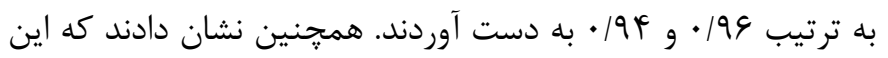
يرسشنامه از روايى همكرايى مطلوبى با برسشنامه Rotter در كروه

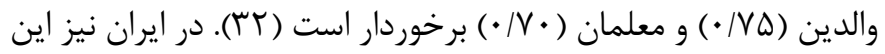
يرسشنامه توسط كاسه :ى در دانشخاه علوم بهزيستى هنجاريابى شده است. در اين مطالعه ضريب اعتبار بازآزمايى يرسشنامه در كروه والدين

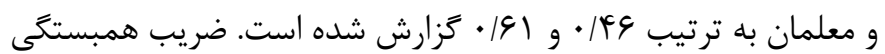

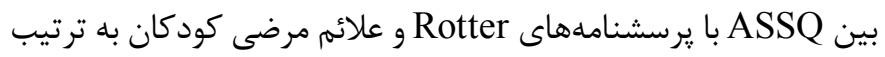

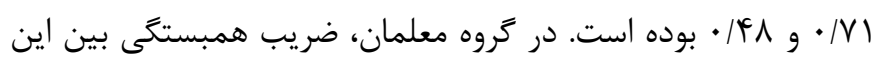

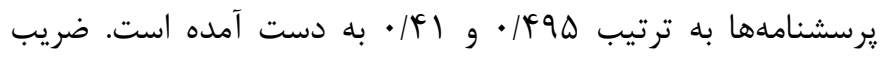

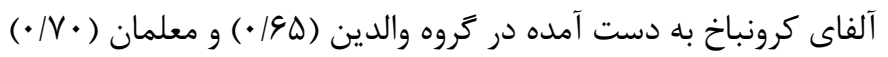
نشان مىدهد كه ASSQ براى غربالكَى كودكان اوتيسم با عملكرد بالا

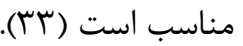

\section{بافته ها}

سن دانشآموزان شركت كننده در اين يزوهش بين 9 تا 9 سال بود.

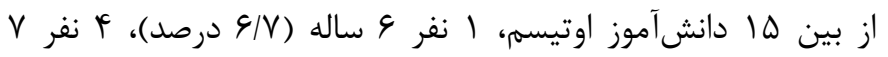

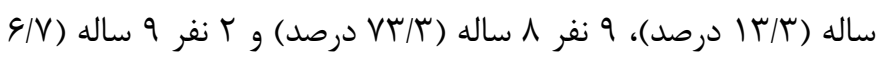

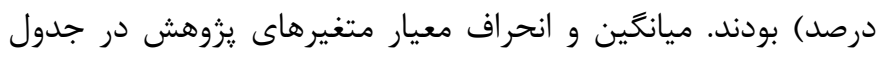

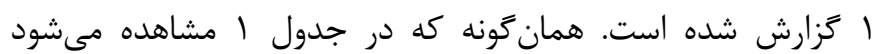

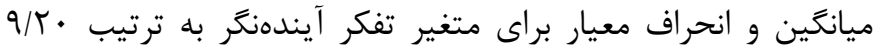

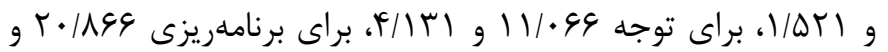

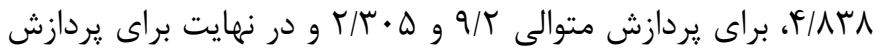

به طور كلى زمانى آزمودنى نمره ؟ را دريافت مى كرد كه توضيحات او هم

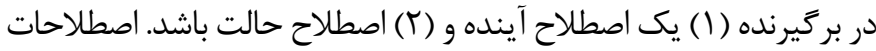
آينده شامل (اقصد دارم، خواهم.... ممكن است...، اي كاش.... مىتوانم....

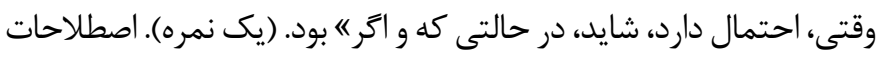

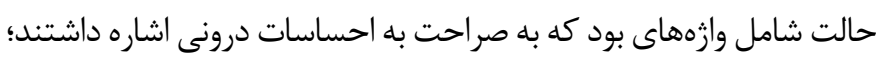

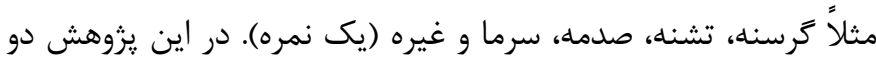
نمرهدهنده انتخابهاى آيتم كودكان و توضيحات شفاهى را به صورت مستقل كدَذارى كردند. توافق براى انتخابهاى آيتم و توضيحات شفاهى

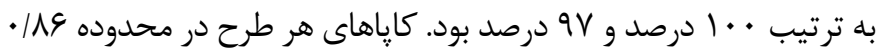

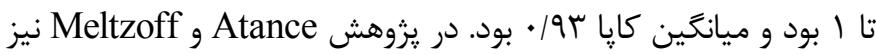
دو نمره دهنده انتخابهاى آيتم كودكان و توضيحات شفاهى را به صورت

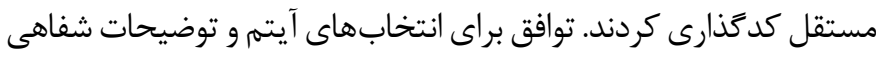

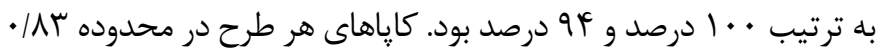

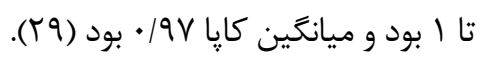

\section{سيستم ارزيابى شناختى -وير ايش دوم (System-second edition} Cognitive Assessment شناختى PASS از فرم كوتاه سيستم ارزيابى شناختى -ويرايش دوم كه

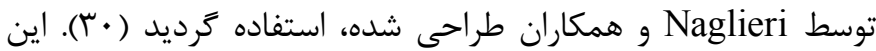
آزمون از ץ خرده مقياس كدهاى برنامهريزى شده (Planned Codes) (در اين خرده مقياس، آزمودنى بايد كدهايى را كه مرتبط با حروف ارائه شده است، در محدوده زمانى خاصى ير كند)، توجه بيانى (Expressive (اين خرده مقياس، شامل دو مجموعه مرتبط با سن است.

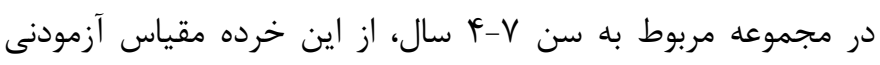

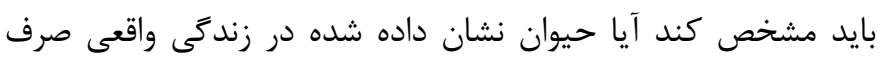

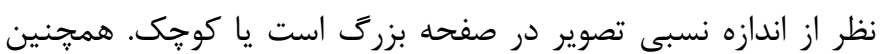

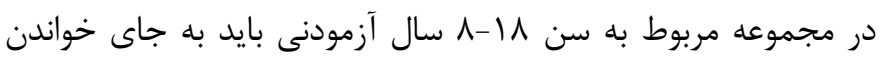
وازه رنگ، جوهرى را نام ببرد كه وازه به آن رنغ است، ماتريسها (در اين قسمت آزمودنى بايد رابطه بين بخشهاى يك آيتم (Matrices) را تشخيص دهد و از 4 گزينه يايين بهترين گزينه را انتخاب كند) و ارقام تشكيل شده است. فرم كوتاه سيسته ارزيابى شناختى -ويرايش (Digit)

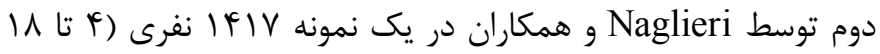

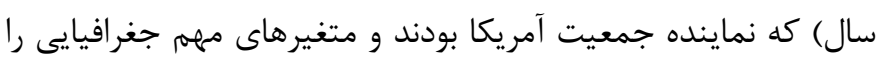

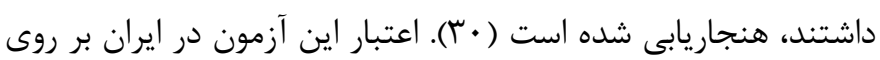

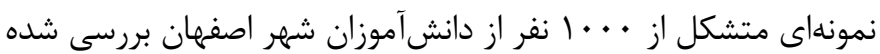
است. ضرايب آلفاى كرونباخ مربوط به خرده مقياسها • م/ • تا DA/• و همجنين ضريب آلفاى كرونباخ نمره كل • 9/ • بوده است. ميانكين نمره خرده مقياسها براى شركت كنندهاى كروه سنى أ تا fأ ساله نشان 


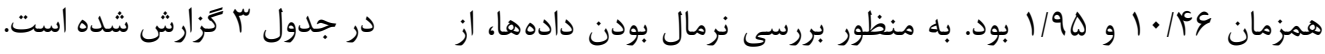
نتايج جدول ب نشان مى مهد ضرايب همبستكى محاسبه شده بين تفكر آزمون شاييروسويلك استفاده شد. نتايج در جدول ب گزارش شده است. آيندهنگر با تمامى فر آيندهاى شناختى PASS به جز فر آيندهاى همزمان همان گونه كه در جدول r مشاهده مى شود، فرض صفر براى نرمال معنادار است. به عبارتى ضريب همبستخى بين تفكر آيندهنگر با توجه

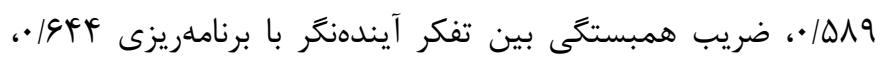
بودن توزيع نمرات تفكر آينده نكر وفرآيندهاى شناختى PASS تاييد مى گردد. به عبارت ديخر نمرات داراى توزيع نرمال است. ضريب همبستكى بين تفكر آيندهنگ با فرآيند متوالى ه99 • است كه

$$
\text { همخى معنادار بودند (ه • (P) }
$$

به منظور بررسى رابطه بين فر آيندهاى شناختى PASS و تفكر آيندهنكر از ضريب همبستخى ييرسون استفاده شد. نتايج ضريب همبستخى ييرسون

جدول 1. آمارههاى توصيفى متغيرهاى يزوهش

\begin{tabular}{|c|c|c|c|}
\hline انحراف معيار & ميانگين & تعداد & متغير ها \\
\hline$|/ \Delta T|$ & $9 / \%$. & 10 & تفكر آيندهنگر \\
\hline$F /|r|$ & $11 / .99$ & 10 & توجه \\
\hline 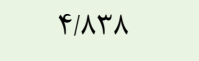 & $r \cdot \mid \wedge 99$ & 10 & برنامهريزى \\
\hline$r / \mu \cdot \Delta$ & $9 / r$ & 10 & يردازش متوالى \\
\hline $1 / 90$ & $1 . / 48$ & 10 & بردازش همزمان \\
\hline
\end{tabular}

جدول r. نتايج آزمون شايِيرو_ويلك در مورد يِيش فرض نرمال بودن توزيع نمرات

\begin{tabular}{|c|c|c|c|}
\hline $\mathbf{P}$ & درجه آزادى & آماره & متغير ها \\
\hline$\cdot / r \Delta F$ & 10 &.$/ 94 \wedge$ & تفكر آيندهنكر \\
\hline$\cdot 1 \cdot \sqrt{ } 9$ & 10 & $\cdot / 199$ & توجه \\
\hline .1119 & 10 & $.19 \cdot 9$ & برنامهريزى \\
\hline$\cdot 1 \cdot 90$ & 10 & $\cdot 11 \wedge 9$ & يردازش متوالى \\
\hline $.1 \cdot 91$ & 10 & $\cdot / 1 \vee \vee q$ & يردازش همزمان \\
\hline
\end{tabular}

جدول rا. ماتريسهاى همبستگى متغيرهاى يزوهش

\begin{tabular}{|c|c|c|c|c|c|}
\hline$\Delta$ & f & r & $r$ & 1 & متغير ها \\
\hline & & & & 1 & تفكر آيندهنكر \\
\hline & & & 1 & $\cdot 10 \wedge 9^{*}$ & توجه \\
\hline & & 1 & $\cdot|8| Y^{*}$ & $\cdot \mid 9 \psi f^{*}$ & برنامهريزى \\
\hline & 1 & $\cdot 10 \cdot r^{*}$ & $\cdot / 4 \vee q$ & $\cdot 1099^{* * *}$ & يردازش متوالى \\
\hline 1 & $\cdot 19 \Delta \Lambda^{*}$ & $\cdot / r \cdot 1$ & • & . ATr & يردازش همزمان \\
\hline
\end{tabular}


مىتوان تببين كرد كه تداخل بالا در توجه به محرك هدف (نقص در مهار نمودن توجه از محرك غيرمرتبط) در كودكان مبتلا به اوتيسم با نهان عملكرد بالا سبب مىشود كه اين كودكان در تكاليف مربوط به تفكر آيندهنكر، به اطلاعات هدف توجه ننمايند و پاسخ هاى نامناسب نشان

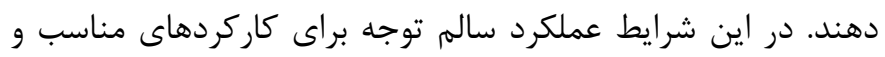

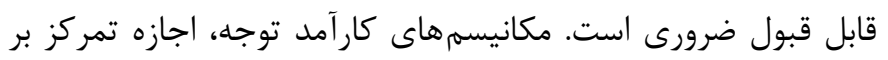

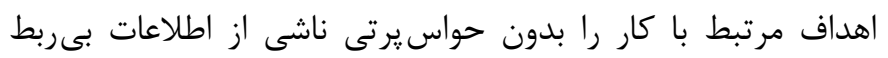

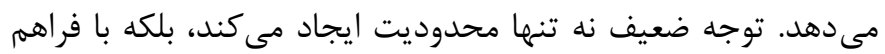
كردن امكان مداخله اطلاعات نامربوط، استفاده از ظرفيت محدود ذخيرهسازى و امكان استفاده از منابع براى يردازش اطلاعات نامربوط،

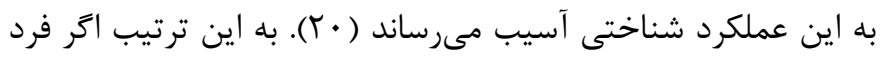

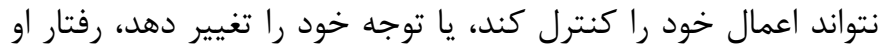

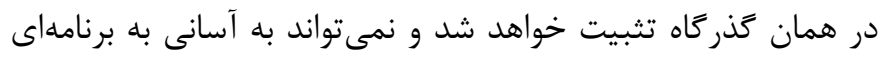

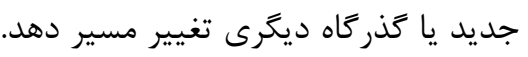

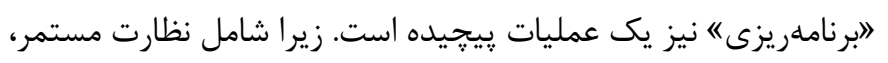

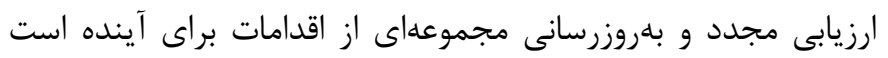
(TF) كودكان مبتلا به اختلال طيف اوتيسم هنحام انجام تكاليف خانكى، ساماندهى فعاليتهاى صبحكاه يا هنكام انجام يك كار خانكى با مشكلاتى مواجه مىشوند، مشكل در انجام اين فعاليتها نيز ممكن است تا حدودى تحت تاثير نواقص "ابرنامهريزى" باشد كه خود تكيه بر

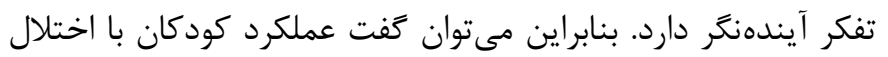

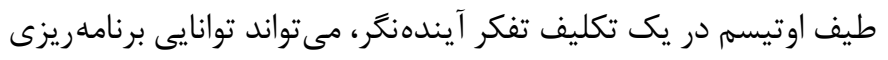

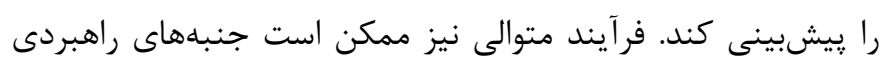

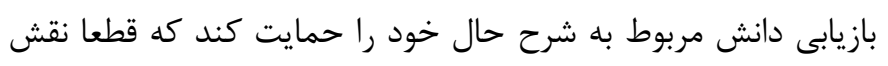

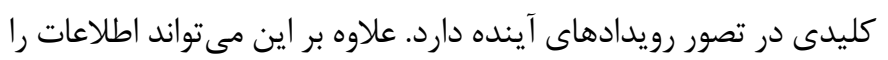

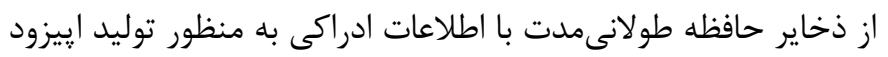
(رخداد) در كذشته و آينده تلفيق كند (·) (Y).

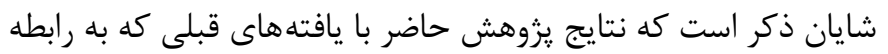

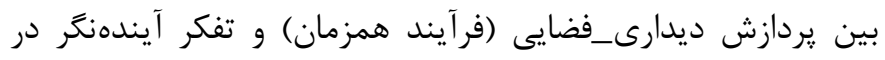

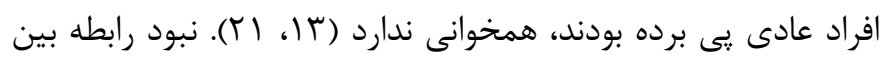

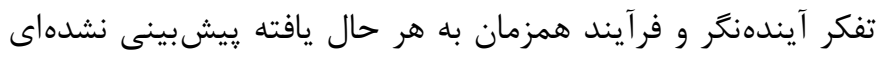

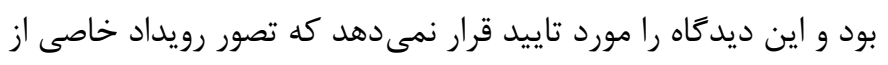

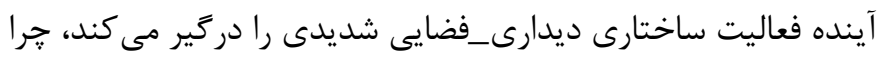
كه فرد بايد جزئيات متعدد را به صورت انعطاف يذير مجددا تركيب كندائ

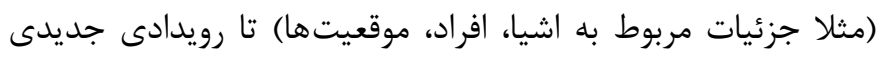
بسازد كه تا آن زمان تجربه نشده است (ه؟، ع؟). يك توضيح براى اين يافته شايد اين باشد كه تفاوتهاى روش شناسى ممكن است اين
هدف از يزوهش حاضر بررسى رابطه فرآيندهاى شناختى PASS و

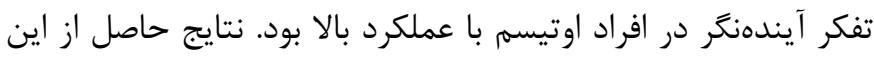

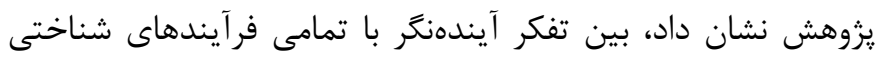

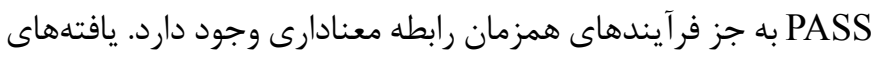

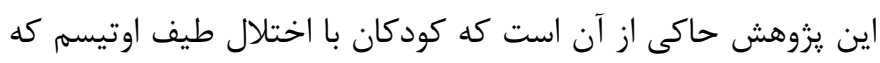

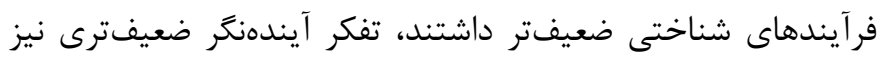

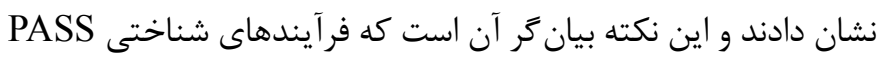
با توانايى تفكر آيندهنكر در كودكان با اختلال طيف اوتيسه رابطه دارد. توانايى كم براى از قبل تجربه كردن رويدادها در آينده، ممكن است

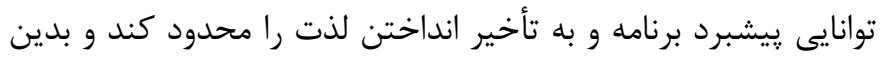
لحاظ ممكن است به عدم انعطافيذيرى رفتارى و تمايل به نظهم معمول

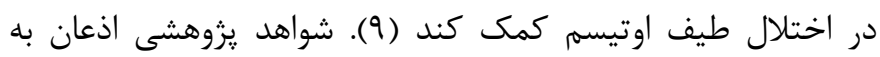

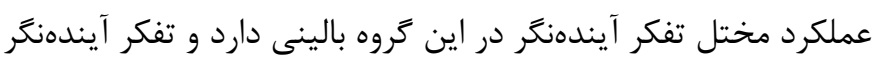

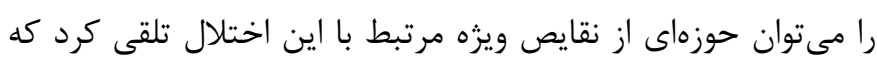

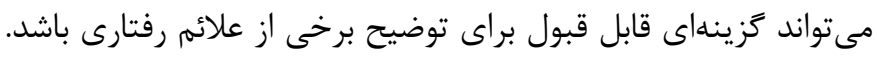

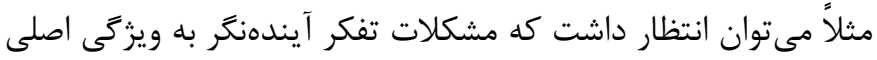

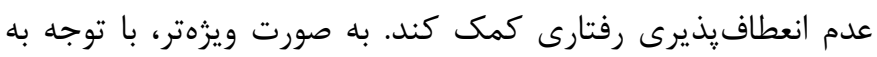

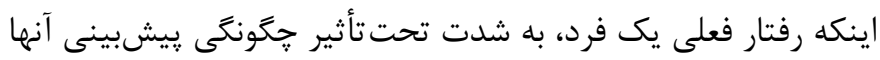

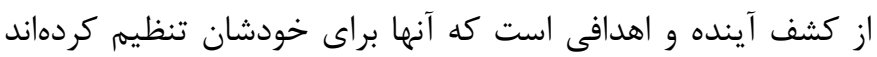

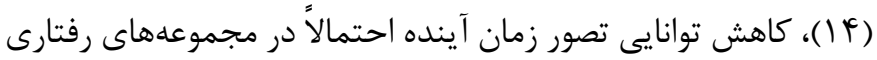

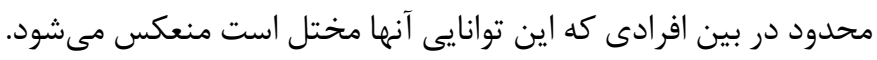

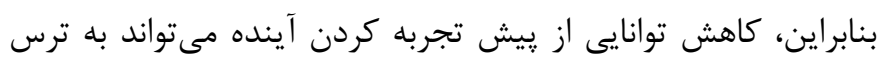

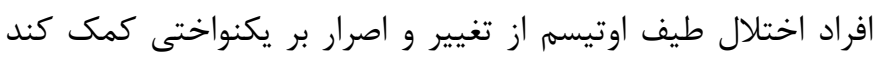
(YF) اساس ديدكاهش را تغيير مىدهد، بايد ويوسته از تغييرى كه ايجاد

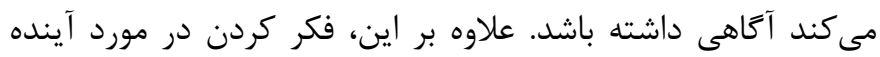
نيازمند تغييرات ديدكاه بين حال و آينده است. توانايىهاى دنبال

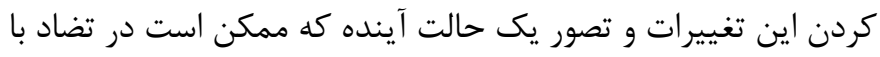
حالت فعلى باشد، به صورت امكانيذير از فر آيندهاى شناختى استفاده

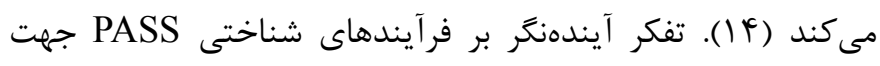

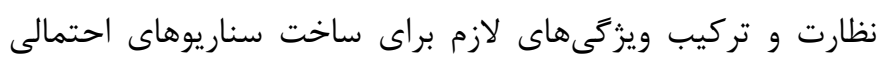

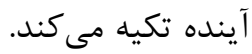

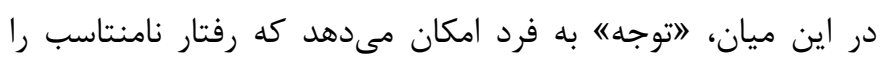

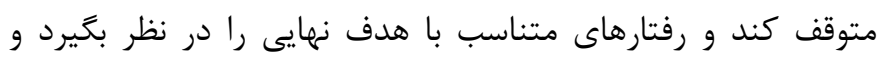

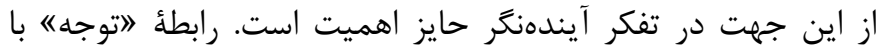
تفكر آيندهنكر در كودكان مبتلا به اوتيسم با عملكرد بالا را اينَّونه 
با ديگران، يادگيرى زبان و مديريت موفق نيازهاى زندگى روزمره

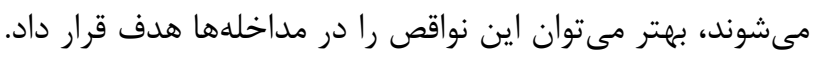

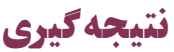

اين مطالعه شواهد مقدماتى در مورد ارتباط برخى از فرايندهاى

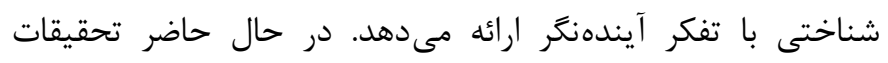

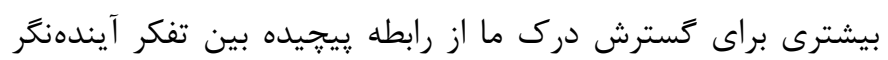

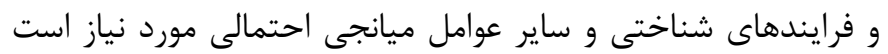

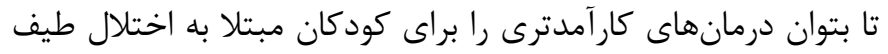

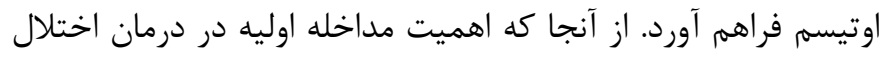

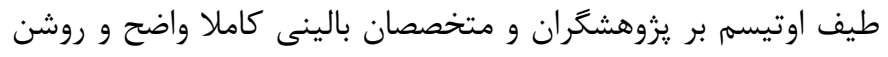

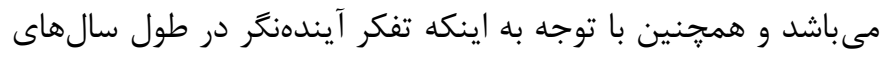

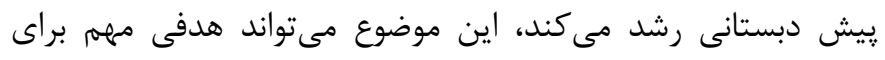

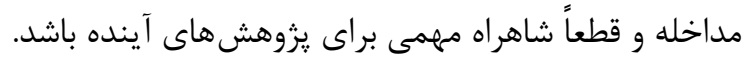

\section{تشكر و قدروانى}

مطالعه حاضر بر كرفته از رساله مقطع دكترى تخصصى روانشناسى و

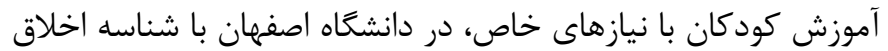
IR.UI.REC.1398.093 است. بدين وسيله از همكارى صميمانه مدرسه دريا در شهر اصفهان در يُشبرد اين يزوهش تشكر و قدردانى

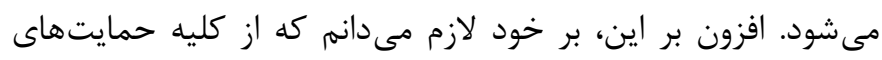

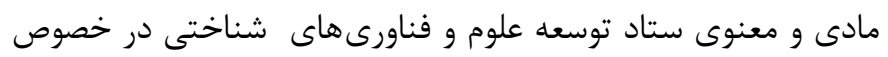
حمايت اين اثر نهايت سياس را داشته باشمه.

\section{References}

1. Association AP. Diagnostic and statistical manual of mental disorders (DSM-5®). Arlington VA:American Psychiatric Publication;2013.

2. Wingate M, Mulvihill B, Kirby RS, Pettygrove S, Cunniff C, Meaney F, et al. Prevalence of autism spectrum disorders-Autism and developmental disabilities monitoring network, 14 sites, United States, 2008. Surveillance summaries, Morbidity and Mortality Weekly Report. 2012;61(3):1-19.

3. Roth I, Rezaie P. Introduction. In Roth I, Rezaie P, editors. Researching the autism spectrum. Cambridge:Cambridge University Press;2011. pp. 1-16.
عدم همخوانى را توجيه كند. مطالعه حاضر تكليف سفر را بر روى شركت كنندكان اجرا كرد و از آنها خواست در مورد مسافرت كردن صحبت كنند (وانمود كنند كه قصد مسافرت دارد) و به يِيشبينى بسيارى از پيامدهاى احتمالى آن بِردازند. حال آنكه يُروهشهاى ييشين از شركت كنندكان خواستند رويدادى را در ذهنشان (براى بـان

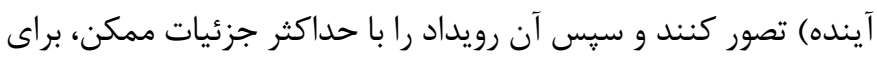

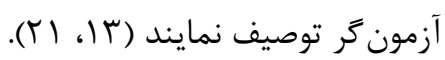
به طور كلى، نتايج فعلى گوياى آن است كه تفكر آيندهنگر به عنوان توانايى تصويرسازى ذهنى از حوادث و رويدادهاى احتمالى آينده با مجموعهاى از فرآيندهاى شناختى در ارتباط است. از جمله محدوديتهاى اين يزوهش، حجم نمونه اندك كودكان اوتيسم با عملكرد بالا بود، به همين دليل نتايج اين يزوهش بايستى با احتياط تعميم داده شود. محدوديت ديخر انجام اين يزوهش بر روى گروه ״سران است، بنابراين يِيشنهاد مى شود كه اين پيزوهش با حجم نمونه

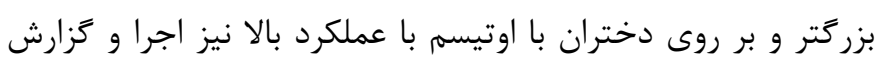

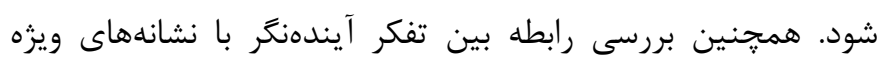

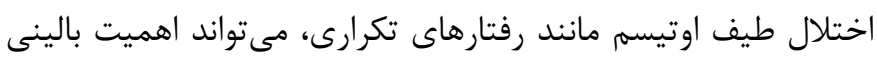
اين يزوهش را افزايش دهد و مسيرى مهلم براى يزوهشهاى آتى باشد. روى هم رفته، شواهد مربوط به جُخونگى تاثيريذيرى تفكر آيندهنگ در اختلال طيف اوتيسم محدود است و مطالعات تجربى بيشترى با استفاده از نمونههاى بزرگتر نياز است تا ماهيت هر گونه مشكل را در اين گروه به وضوح مشخص كند. با افزايش درك از نواقص دقيق شناختى كه مانع توانايى كودكان با اختلال طيف اوتيسم براى تعامل

4. Nejati V, Izadi-Najafabadi S. Comparison of executive functions in high-function autistic children and their typical matched peers. Journal of Research in Rehabilitation Sciences. 2012;8(1):28-39. (Persian)

5. Yasuda Y, Hashimoto R, Ohi K, Yamamori H, Fujimoto M, Umeda-Yano S, et al. Cognitive inflexibility in Japanese adolescents and adults with autism spectrum disorders. World Journal of Psychiatry. 2014;4(2):42-48.

6. Brunsdon VE, Colvert E, Ames C, Garnett T, Gillan N, Hallett $\mathrm{V}$, et al. Exploring the cognitive features in children with autism spectrum disorder, their co-twins, and typically devel- 
oping children within a population-based sample. Journal of Child Psychology and Psychiatry. 2015;56(8):893-902.

7. Baron-Cohen S. Precursors to a theory of mind: Understanding attention in others. In Whiten A, Byme RW, editors. Natural theories of mind: Evolution, development, and simulation of everyday mind reading. Cambridge:Basil Blackwell;1991. pp. 233-251.

8. Heidari T, Shamive Isfahani A, Faramarzi S. The Comparison theory of mind dimension in autism children and normal children Isfahan city. Knowledge \& Research in Applied Psychology. 2011;12(45):64-70. (Persian)

9. Lind SE, Bowler DM. Episodic memory and episodic future thinking in adults with autism. Journal of Abnormal Psychology. 2010;119(4):896-905.

10. Lind SE, Williams DM. The association between past and future oriented thinking: Evidence from autism spectrum disorder. Learning and Motivation. 2012;43(4):231-240.

11. Terrett G, Rendell PG, Raponi-Saunders S, Henry JD, Bailey PE, Altgassen M. Episodic future thinking in children with autism spectrum disorder. Journal of Autism and Developmental Disorders. 2013;43(11):2558-2568.

12. Hanson LK, Atance CM. Brief report: Episodic foresight in autism spectrum disorder. Journal of Autism and Developmental Disorders. 2014;44(3):674-684.

13. D’Argembeau A, Ortoleva C, Jumentier S, Van Der Linden M. Component processes underlying future thinking. Memory \& Cognition. 2010;38(6):809-819.

14. Suddendorf T, Corballis MC. The evolution of foresight: What is mental time travel, and is it unique to humans?. Behavioral and Brain Sciences. 2007;30(3):299-313.

15. Boyer P. Evolutionary economics of mental time travel?. Trends in Cognitive Sciences. 2008;12(6):219-224.

16. Suddendorf T, Corballis MC. Mental time travel and the evolution of the human mind. Genetic, Social, and General Psychology Monographs. 1997;123(2):133-167.

17. Jackson LK, Atance CM. Future thinking in children with autism spectrum disorders: A pilot study. Journal on Developmental Disabilities. 2008;14(3):40-45.
18. Marini A, Ferretti F, Chiera A, Magni R, Adornetti I, Nicchiarelli S, et al. Brief report: Self-based and mechanical-based future thinking in children with autism spectrum disorder. Journal of Autism and Developmental Disorders. 2016;46(10):3353-3360.

19. Hanson LK, Atance CM, Paluck SW. Is thinking about the future related to theory of mind and executive function? Not in preschoolers. Journal of Experimental Child Psychology. 2014;128:120-137.

20. Zavagnin M, De Beni R, Borella E, Carretti B. Episodic future thinking: The role of working memory and inhibition on age-related differences. Aging Clinical and Experimental Research. 2016;28(1):109-119.

21. Buckner RL, Carroll DC. Self-projection and the brain. Trends in Cognitive Sciences. 2007;11(2):49-57.

22. Hill PF, Emery LJ. Episodic future thought: Contributions from working memory. Consciousness and Cognition. 2013;22(3):677-683.

23. Das JP, Naglieri JA, Kirby JR. The assessment of cognitive processes: The PASS theory of intelligence. 1st ed. Boston:Allyn \& Bacon;1994.

24. Power JD, Cohen AL, Nelson SM, Wig GS, Barnes KA, Church JA, et al. Functional network organization of the human brain. Neuron. 2011;72(4):665-678.

25. Kendeou P, Papadopoulos TC, Spanoudis G. Reading comprehension and PASS theory. In: Das JP, editor. Cognition, intelligence, and achievement. Cambridge:Academic Press;2015. pp. 117-136.

26. Nishanimut SP, Padakannaya P. Cognitive assessment system: A review. Psychological Studies. 2014;59(4):345-350.

27. Taddei S, Contena B. Brief report: Cognitive performance in Autism and Asperger's Syndrome: What are the differences?. Journal of Autism and Developmental Disorders. 2013;43(12):2977-2983.

28. Taddei S, Contena B. Cognitive processes in ADHD and Asperger's disorder: Overlaps and differences in PASS profiles. Journal of Attention Disorders. 2017;21(13):1087-1093. 
29. Atance CM, Meltzoff AN. My future self: Young children's Developmental Disorders. 1999;29(2):129-141.

ability to anticipate and explain future states. Cognitive Devel- 33. Kasechi M, Behnia F, Mirzaei H, Rezafiani M, Farzi M. opment. 2005;20(3):341-361. Validity and reliability of Persian version of high-functioning

30. Naglieri JA, Das JP, Goldstein S. Cognitive assessment autism spectrum screening questionnaire age 7-12. Pajouhan system-second edition: Brief. Austin, TX:Pro-Ed Publishing Scientific Journal. 2013;12(1):45-54. (Persian)

Company;2014.

34. Hill EL. Executive dysfunction in autism. Trends in Cogni-

31. Samadi M, Ghamarani A, Faramazi S. The study of psycho- tive Sciences. 2004;8(1):26-32.

metric characteristics of cognitive assessment system, second 35. Schacter DL, Addis DR. On the constructive episodic simedition-brief in Isfahan. Journal of Applied Psychology Re- ulation of past and future events. Behavioral and Brain Sciencsearch. In Press. (Persian) es. 2007;30(3):331-332.

32. Ehlers S, Gillberg C, Wing L. A screening questionnaire for 36. Schacter DL, Addis DR, Buckner RL. Episodic simulation Asperger syndrome and other high-functioning autism spec- of future events: Concepts, data, and applications. Annals of trum disorders in school age children. Journal of Autism and the New York Academy of Sciences. 2008;1124:39-60. 